\title{
Renal Resistive Index as an early Predictor of Contrast Induced Nephropathy in Patients Undergoing Coronary Angiography
}

\author{
Hesham TAHA*, Hussein EL-FISHAWY, Assem HASHAD and Osama AL-SAYED \\ Department of Cardiovascular Medicine, Cairo University, Egypt
}

Submission: January 18, 2019; Published: February 25, 2019

*Corresponding author: Hesham TAHA, Department of Cardiovascular Medicine, Cairo University, Cairo, Egypt

\begin{abstract}
Background: Contrast induced acute kidney injury (CI-AKI) is a common and serious complication of contrast agents used in imaging studies. Clinical markers useful for early detection of CI-AKI and prediction of outcome are needed in order to speed diagnosis and implementation of renal protective measures. In septic shock, postoperative setting of cardiac surgery and TAVI subjects, an increased Doppler Renal Resistive Index (RRI) is a predictor of AKI. This study aims to test the hypothesis that Doppler-based renal resistive index would similarly predicts contrast induced acute kidney injury in patients undergoing cardiac catheterization.
\end{abstract}

Methods: We enrolled 100 patients undergoing cardiac catheterization and at risk of CI-AKI. All presented with at least two CI- AKI risk factors and were free of other identifiable causes of acute kidney injury or arrhythmia. Doppler RRI was measured before and at first day after catheterization. CI-AKI was assessed, defined by serum creatinine increase $25 \%$ above the pre-procedural baseline or rise in serum creatinine of $>0.5 \mathrm{mg} / \mathrm{dl}$ from baseline value or a $>25 \%$ decrease in eGFR within 5 days after cardiac catheterization.

Results: Nineteen subjects developed CI- AKI in the first five days post-procedure, with two requiring dialysis. Post procedural RRI value was higher in CI-AKI subjects [RRI: $0.77 \pm 0.02$ with CI- AKI vs $0.67 \pm 0.03$ without $\mathrm{CI}-\mathrm{AKI},(\mathrm{P}<0.001)$ ]. In addition, the RRI increased significantly in the first day after the procedure [from RRI $0.7 \pm 0.38$ preprocedural to $0.77 \pm 0.02$ in patients developing CI-AKI $(\mathrm{p}<0.001)$ ]. Post procedural RRI $>0.744$ predicted CI- AKI with a sensitivity of $94 \%$ and specificity of $92 \%$.

Conclusion: Measurement of the Doppler-based RRI early post-catheterization in high risk patients enabled early prediction of contrast induced acute kidney injury.

Keywords: Acute Kidney injury; Contrast; Doppler; Resistive index; Cardiac catheterization

\section{Introduction}

Contrast-induced nephropathy is a common and serious complication of contrast agents used in imaging studies and is the third leading cause of acute kidney injury in hospitalized patients [1]. Patients who develop contrast-induced nephropathy after percutaneous coronary intervention sustain an increase in both short and long-term mortality and increase in length of hospital stay $[2,3]$. However, in the periprocedural period early detection of CI-AKI is difficult as it's hampered by the absence of early predictors of renal function and the delayed increase in the level of conventional markers, such as serum creatinine level or clearance [4]. Early recognition of CI-AKI might allow for optimization of renal condition and more intensive renal sparing actions.

Renal vasoconstriction resulting in medullary hypoxia is considered to play a significant role in the pathogenesis of CI- AKI
$[5,6]$. RRI has recently been suggested for assessing these changes in renal perfusion and it has been shown that RRI correlates with serum creatinine level and also predicts AKI in post TAVI setting, [7] cardiac surgery patients [8] and in septic shock patients admitted to the intensive care unit [9]. This study aims to test the hypothesis that Doppler-based renal resistive index would similarly predicts contrast induced acute kidney injury in patients undergoing cardiac catheterization.

\section{Methods}

\section{Patient population}

This prospective observational study that enrolled 100 patients undergoing cardiac catheterization in Cairo University Hospital between September 2015 and September 2016. We 
included consecutive subjects with at least two of the following known risk factors for CI-AKI: Glomeruler Filtration Rate (eGFR) $<90 \mathrm{ml} / \mathrm{min} / 1.73 \mathrm{~m} 2$, age $>60 \mathrm{yr}$, peripheral vascular disease, diabetes, heart failure and anemia. Exclusion criteria were the following: renal artery stenosis, non-sinus cardiac rhythm and presence of other identifiable causes of acute kidney injury such as sepsis, hypotension and nephrotoxic drugs. The primary endpoint of the study was the occurrence of contrast induced acute kidney injury defined as relative increase in serum creatinine by $25 \%$ between baseline level and peak level or rise in serum creatinine of $>0.5 \mathrm{mg} / \mathrm{dl}$ from baseline value or a $>25 \%$ decrease in eGFR within 5 days after cardiac catheterization. For each subject, basic characteristic data, standard treatments, Mehran's Score [10] and main procedure data were recorded. Outcome variables, such as the need for renal replacement therapy and in hospital mortality were also recorded.

The study protocol had been approved by the local ethics committee, and all patients had given informed consent.

\section{Renal duplex evaluation}

The Renal Resistive Index (RRI) measurement was performed by trained sonographer before and within 24 hours after coronary angiography using commercially available machines in our facility (Philips Envisor HD) with $2.5 \mathrm{MHz}$ pulsed wave Doppler probe. The patients were examined in a supine position using a lateral or postero-lateral approach. First correct B-mode acoustic window with a precise regulation of focus and gain was acquired; subsequently, the color box was opened.

With the activation of the pulsed wave Doppler module, the sample volume was placed in the lumen of proximal interlobar arteries and the speed-time curve was recorded. The Doppler gain was set to obtain a clear outline of flow waves with minimal background noise. The Doppler spectrum was considered optimal when at least three similar consecutive waveforms visualized. The renal RI was calculated as follows: (Peak systolic velocity End diastolic velocity)/peak systolic velocity. The results from three consecutive measurements on both kidneys were averaged. Normal RI values in adults are in the range of $0.47-0.70$ with a difference between two kidneys of $5-8 \%$. The RRI value is independent of the angle between the ultrasound beam and blood flow (Figure 1).

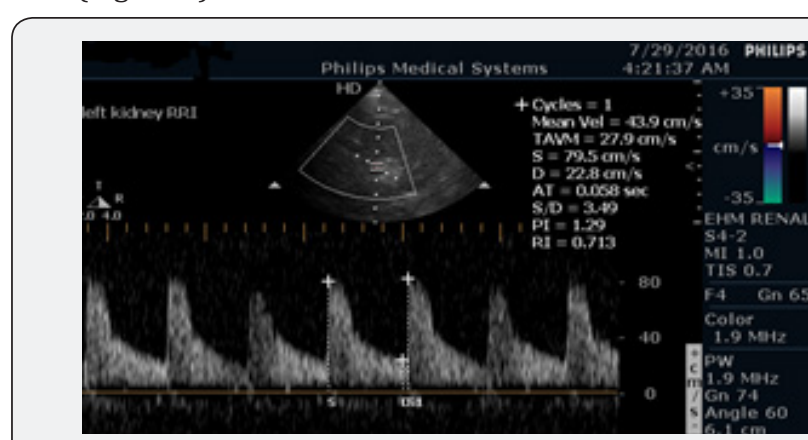

Figure 1: Calculation of the Doppler-based renal resistance index. (Peak systolic velocity - End diastolic velocity) / peak systolic velocity.

\section{Laboratory analyses}

BUN and Creatinine were measured using Dimension auto analyzer (supplied by Siemens HealthCare Diagnostics Inc.), with a reference range of $0.4-1.2 \mathrm{mg} / \mathrm{dl}$ for creatinine and $3-20 \mathrm{mg} /$ $\mathrm{dl}$ for BUN. Both were assessed before coronary angiography as a reference value, and reassessed repeatedly after angiography, until peak serum creatinine value was reached also Creatinine Clearance was estimated by Cockcroft-Gault Equation [11].

$$
\mathrm{eC}_{c \tau}=\frac{(140-\text { Age }) \times \text { Mass }(\text { in Kinlogram }) \times[0.85 \text { if Female })}{72 \times \text { Serum Creatinine }(\text { in } \mathrm{mg} / \mathrm{dL})}
$$

Haemoglobin and hematocrite were measured by coulter $\mathrm{LH}$ 750 Analyzer with a cut off Hemoglobin value for anemia < 13gm/ $\mathrm{dl}$ for males and $12.3 \mathrm{gm} / \mathrm{dl}$ for females and hematocrite value $<39 \%$ for men and $<36 \%$ for women.

\section{Statistical analysis}

Data were coded and entered using the statistical package SPSS (Statistical Package for the Social Sciences). Data was summarized using mean and standard deviation in quantitative data and using frequency (count) and relative frequency (percentage) for categorical data. Comparisons between quantitative variables were done using the non-parametric Kruskal-Wallis and MannWhitney tests. For comparing categorical data, Chi square $(\chi 2)$ test was performed. Exact test was used instead when the expected frequency is less than 5. Correlations between quantitative variables were done using Spearman correlation coefficient. ROC curve was constructed with area under curve analysis performed to detect best cutoff values for detection of CIN. Logistic regression was done to detect independent predictors of CIN. P-values less than 0.05 were considered as statistically significant.

\section{Results}

\section{Baseline characteristics}

In total, 100 patients were enrolled in this study between September 2015 and September 2016. In all study subject's renal artery resistive index measurement was done before and within 24 hours after cardiac catheterization.

Nineteen subjects developed CI-AKI, two of whom required dialysis (Figure 2). Subjects who developed CI-AKI were older $(63.11 \pm 9.5$ vs $56.33 \pm 7.11$ years $p=0.003)$ and suffered more frequently from heart failure $(\mathrm{p}=0.02)$ and the development of CI-AKI was associated with diuretics administration $(\mathrm{p}=0.001)$. Baseline characteristics are summarized in Table 1.

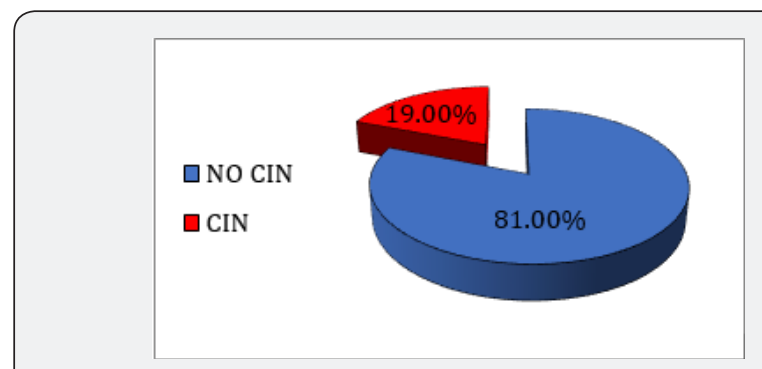

Figure 2: Percentage of patients who developed $\mathrm{Cl}-\mathrm{AKI}$ in the studied Population. 
Table 1: Baseline characteristics according to occurrence of CI-AKI.

\begin{tabular}{|c|c|c|c|c|}
\hline & Total & No CI-AKI ( $n=81)$ & CI-AKI (n=19) & P value \\
\hline \multicolumn{5}{|c|}{ Demographics, clinical data and CI-AKI related risk factors } \\
\hline Age, years mean $( \pm$ SD $)$ & $57.62( \pm 8)$ & $56.33( \pm 7.11)$ & $63.11 \pm 9.5$ & 0.003 \\
\hline Male gender, n (\%) & $78(78 \%)$ & $64(78.8 \%)$ & $14(73.7 \%)$ & 0.759 \\
\hline Weight, kg mean $( \pm \mathrm{SD})$ & $79.48( \pm 12.2)$ & $80.26( \pm 12.4)$ & $76.2( \pm 11)$ & 0.238 \\
\hline Smoking, n (\%) & $63(63 \%)$ & $51(63 \%)$ & $12(63.2 \%)$ & 0.987 \\
\hline DM, n (\%) & $53(53 \%)$ & $41(51.9 \%)$ & $12(63.2 \%)$ & 0.324 \\
\hline HTN, n (\%) & $50(50 \%)$ & $42(51.9 \%)$ & $8(42.1 \%)$ & 0.444 \\
\hline Heart failure $(n, \%)$ & $55(55 \%)$ & $40(49.4 \%)$ & $15(78.9 \%)$ & 0.02 \\
\hline Stroke n, (\%) & $7(7 \%)$ & $6(7.4 \%)$ & $1(5.3 \%)$ & 1 \\
\hline Anemia, n (\%) & $32(32 \%)$ & $25(30.9 \%)$ & $7(36.8 \%)$ & 0.615 \\
\hline \multicolumn{5}{|c|}{ Drug usage } \\
\hline NSAID, n (\%) & $2(2 \%)$ & $2(2.5 \%)$ & $0(0)$ & 0.99 \\
\hline ACEI, n (\%) & $60(60 \%)$ & $49(60.5 \%)$ & $11(57.9)$ & 0.835 \\
\hline Diuretics, n (\%) & $38(38)$ & $24(29.6 \%)$ & $14(73.7 \%)$ & $<0.001$ \\
\hline Metformin, n (\%) & $10(10 \%)$ & $9(11.1 \%)$ & $1(5.3 \%)$ & 0.682 \\
\hline \multicolumn{5}{|c|}{ Presentation } \\
\hline STEMI, n (\%) & $26(26 \%)$ & $20(24.7 \%)$ & $6(31.6 \%)$ & 0.916 \\
\hline NSTEMI, n (\%) & $30(30 \%)$ & $24(29.6 \%)$ & $6(31.6 \%)$ & \\
\hline UA, n (\%) & $30(30 \%)$ & $24(29.6 \%)$ & $6(31.6 \%)$ & \\
\hline Stable Angina, n (\%) & $11(11 \%)$ & $10(12.3 \%)$ & $1(5.3 \%)$ & \\
\hline Cardiomyopathy, n (\%) & $3(3 \%)$ & $3(3.7 \%)$ & $0(0)$ & \\
\hline
\end{tabular}

\section{Peri-procedural data}

Patients who developed CI-AKI were characterized by increased Mehran's score for prediction contrast induced nephropathy $(10.8 \pm 3.15$ vs $6.67 \pm 2.36$ in non-CI-AKI $\mathrm{p}=0.001)$ and decreased creatinine clearance levels $(67.9 \pm 26.7$ vs $85.1 \pm 21.4$ $\mathrm{p}=0.015)$. However, baseline creatinine levels weren't significantly different between two groups. The pre-procedural RRI was significantly higher in patients who subsequently developed CIAKI after cardiac catheterization Table 2.

Table 2: Peri-procedural characteristics and measurements according to occurrence of $\mathrm{Cl}-\mathrm{AKI}$.

\begin{tabular}{|c|c|c|c|c|c|}
\hline & & Total $(n=100)$ & No CI-AKI $(n=81)$ & CI-AKI (n=19) & $P$ value \\
\hline \multicolumn{6}{|c|}{ Pre-procedural } \\
\hline \multicolumn{2}{|c|}{ Pre Creat (mean \pm SD) } & $1.15 \pm .37$ & $1.11 \pm 0.27$ & $1.31 \pm 0.63$ & 0.428 \\
\hline \multicolumn{2}{|c|}{ Pre eGFR (mean \pm SD) } & $82.29 \pm 23$ & $85.1 \pm 21.4$ & $67.9 \pm 26.7$ & 0.015 \\
\hline \multicolumn{2}{|c|}{ Pre RRI (mean \pm SD) } & $0.671 \pm .044$ & $0.663 \pm 0.41$ & $0.708 \pm 0.038$ & $<0.001$ \\
\hline \multicolumn{6}{|c|}{ Procedural } \\
\hline \multirow{2}{*}{$\begin{array}{c}\text { Type of procedure, } \\
\text { n (\%) }\end{array}$} & Diagnostic & $31(31.0 \%)$ & $25(30.9 \%)$ & $6(31.6 \%)$ & \multirow{2}{*}{0.952} \\
\hline & Interventional & $69(69.0 \%)$ & $56(69.1 \%)$ & $13(68.4 \%)$ & \\
\hline \multirow{4}{*}{$\begin{array}{l}\text { Angiographic } \\
\text { disease, n (\%) }\end{array}$} & None & $3(3.0 \%)$ & $2(2.5 \%)$ & $1(5.3 \%)$ & \multirow{4}{*}{0.002} \\
\hline & Single vessel & $38(38.0 \%)$ & $34(42.0 \%)$ & $4(21.1 \%)$ & \\
\hline & Two vessel & $38(38.0 \%)$ & $34(42.0 \%)$ & $4(21.1 \%)$ & \\
\hline & Three vessel & $21(21.0 \%)$ & $11(13.6 \%)$ & $10(52.6 \%)$ & \\
\hline \multirow{2}{*}{$\begin{array}{c}\text { Type of contrast, } n \\
(\%)\end{array}$} & High osmolar & $66(66.0 \%)$ & $54(66.7 \%)$ & $12(63.2 \%)$ & \multirow{2}{*}{0.771} \\
\hline & Low osmolar & $34(34.0 \%)$ & $27(33.3 \%)$ & $7(36.8 \%)$ & \\
\hline \multicolumn{2}{|c|}{ Volume of contrast } & $175.80 \pm 81.48$ & $168.52 \pm 68.50$ & $206.84 \pm 120.00$ & 0.216 \\
\hline \multicolumn{6}{|c|}{ Post-procedural } \\
\hline \multicolumn{2}{|c|}{ Post creat } & $1.35 \pm .83$ & $1.09 \pm .25$ & $2.44 \pm 1.41$ & $<0.001$ \\
\hline
\end{tabular}


Journal of Cardiology \& Cardiovascular Therapy

\begin{tabular}{|c|c|c|c|c|}
\hline $\boldsymbol{\Delta}$ creat & $.20 \pm .66$ & $0.01 \pm .16$ & $1.13 \pm 1.08$ & $<0.001$ \\
\hline Post eGFR & $77.58 \pm 27.93$ & $86.42 \pm 21.75$ & $39.91 \pm 18.40$ & $<0.001$ \\
\hline $\boldsymbol{\Delta G F R}$ & $4.71 \pm 17.66$ & $0.74 \pm 13.21$ & $27.96 \pm 15.31$ & $<\mathbf{0 . 0 0 1}$ \\
\hline $\boldsymbol{\Delta G F R \%}$ & $6.25 \pm 23.12$ & $1.93 \pm 15.76$ & $41.10 \pm 15.85$ & $<\mathbf{0 . 0 0 1}$ \\
\hline Post RRI & $.693 \pm .053$ & $0.676 \pm 0.041$ & $.768 \pm .026$ & $<0.001$ \\
\hline $\boldsymbol{\Delta}$ RRI & $.022 \pm .026$ & $.013 \pm .015$ & $.061 \pm .029$ & $<\boldsymbol{0 . 0 0 1}$ \\
\hline Mehran score (mean $\mathbf{S S D}$ & $7.45 \pm 3$ & $6.67 \pm 2.36$ & $10.8 \pm 3.15$ & $<\boldsymbol{0 . 0 0 1}$ \\
\hline Dialysis & $2(10.5 \%)$ & 0 & $2(10.5 \%)$ & $<\boldsymbol{0 . 0 0 1}$ \\
\hline In hospital mortality & $4(4 \%)$ & $2(2.25 \%)$ & $2(10.5)$ & $\mathbf{0 . 1 6 2}$ \\
\hline
\end{tabular}

The development of CI-AKI was associated with multi-vessel disease (52.6\% in comparison with no CI-AKI $13.6 \% \mathrm{p}=0.002)$.

Post-procedural renal resistive index and contrast induced AKI

In patients developing CI-AKI, a significant increase of the RRI baseline values (from $0.708 \pm .038$ to $0.77 \pm 0.026 \mathrm{p}=<0.001$ ) was observed in first day after procedure Figure 3.

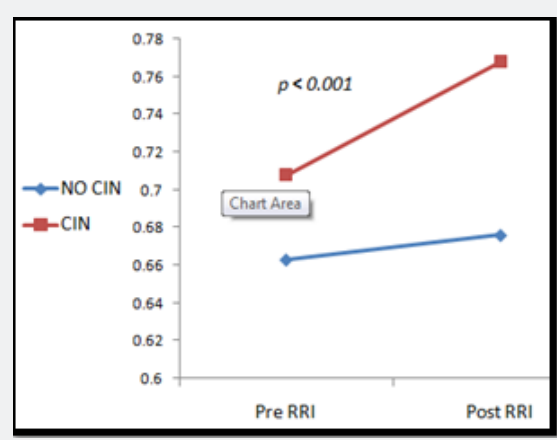

Figure 3: Pre and post procedural RRI measurement in the two groups.

In ROC curve analysis, we calculated a cut-off value of the RRI for the prediction of CI-AKI. At first day after cardiac catheterization, a RRI $>0.744$ was able to predict CI-AKI with a sensitivity of $94 \%$ and a specificity of $92 \%$, and was superior to the prediction of CI-AKI by Mehran's risk score. Also change in RRI $(\Delta \mathrm{RRI})$ achieved high specificity and sensitivity values as shown in Figure 4.

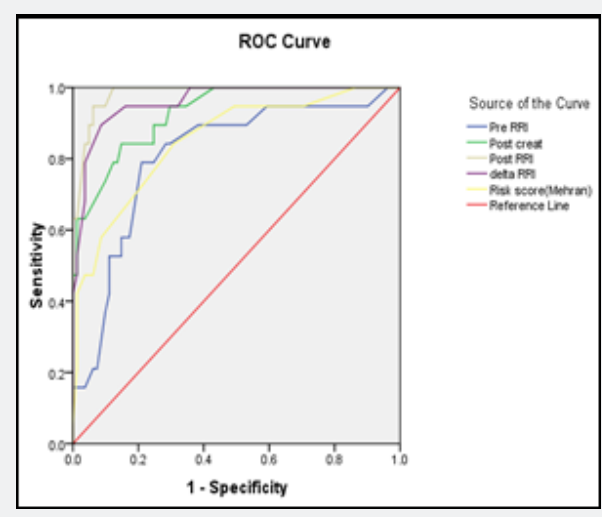

Figure 4: Prediction of $\mathrm{Cl}-\mathrm{AKI}$ with ROC curves.
There was moderate correlation between Post-RRI and postcreatinine values (Correlation Coefficient $=0.406, \mathrm{P}=<0.001$ ) as shown in Figure 5.

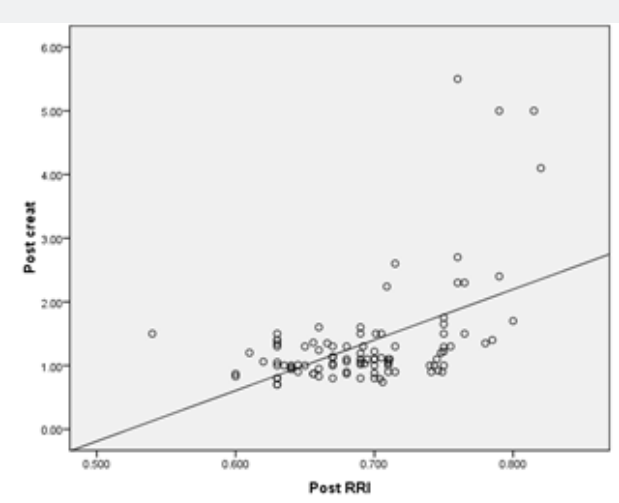

Figure 5: Correlation between Post-RRI and post-creatinine value.

\section{Discussion}

The main finding of our study was the ability of RRI to predict CI-AKI with a high level of sensitivity and specificity at an early stage after cardiac catheterization, which is within the first 24 hours following cardiac catheterization. This parameter outperformed conventional serum creatinine, which rise was shown to be delayed after the procedure.

The overall occurrence of CI-AKI in the development set of Mehran risk score for patients undergoing PCI was $13.1 \% .10$ In our study subjects; the incidence of AKI was 19\%, with $2 \%$ requiring dialysis and mean value of Mehran risk score in our study subjects was 7.5. These results are comparable with Mehran study.

Pathophysiology of CI-AKI and its link to renal resistive index.

Renal vasoconstriction resulting in medullary hypoxia, possibly mediated by alterations in nitric oxide, endothelin, or adenosine is considered to play a significant role in the pathogenesis of CI- AKI [12,13]. RRI can be used for assessing these renal perfusion changes, which only subsequently results in accumulation of serum Creat and overt CI-AKI. The RRI has recently been suggested for assessing changes in renal perfusion in post TAVI setting,7 cardiac surgery patients8 and in critically ill patients admitted to the intensive care unit [14-16]. 


\section{Post procedural RRI and contrast induced AKI}

In present study the post procedural RRI threshold of $>0.744$ achieved $94 \%$ sensitivity and $92 \%$ specificity closely matching values found in similar studies which investigated potential role of RRI in predicting AKI. Reviewing recently published studies, there is an interesting work presented by Bossard et al. [8], who studied 65 patients after cardiac bypass graft surgery with risk factors for AKI and indicated that in the immediate postoperative period RRI value $>0.74$ predicted the occurrence of delayed AKI with a sensitivity of $85 \%$ and a specificity of $94 \%$. Moreover, in a study of 51 critically ill patients hospitalized in an intensive care unit, Darmon et al. [15] showed that RRI $>0.795$ identified patients with persistent AKI ( $>3$ days) with a sensitivity of $92 \%$ and a specificity of $85 \%$, in line with these results, Sinning et al. [7] studied 132 high risk subjects undergoing TAVI and indicated that RRI $>0.85$ predicted post interventional AKI with a sensitivity of $58 \%$ and specificity of $86 \%$. This high RRI threshold in contrast to our study might be explained by significantly higher mean subject age in this study ( $80.9 \pm 6.6$ years) in comparative to our study mean age ( $57.6 \pm 8$ years). Hence, our data closely match those of published literature, supporting the use of a threshold value of RRI >0.74-0.85 in predicting AKI in different clinical scenarios.

\section{Clinical Implications}

Based on our analysis, RRI allows the diagnosis of CI-AKI to be anticipated by few days. Routine evaluation of RRI in subjects at risk of CI- AKI could encourage clinicians to increase duration and frequency of conventional renal markers monitoring and to maximize renal-sparing actions. Such a prompt response to CIAKI would not be possible if the therapeutic strategy is based on delayed criteria, such as the increase in serum creat.

\section{Study Limitations and Future Direction}

- $\quad$ First, our study is small sized study; a much larger study sample is mandatory to confirm our results.

- $\quad$ Second, we enrolled a mixed population of patients with different cardiovascular and renal risk factors. Such mixed sample may be a misleading factor.

- $\quad$ Third, we selected subjects presenting with an increases risk for CI-AKI. Extrapolation of our finding to low risk subjects is of obvious interest.

\section{Conclusion}

Our study showed that in high risk patients for contrast induced acute kidney injury, the Doppler based renal resistive index that is measured early after cardiac catheterization is useful in predicting contrast induced acute kidney injury in contrast to serum creatinine related markers, whose increase were shown to be delayed. Assessing RRI might allow for optimizing periprocedural renal function sparing strategies. Further studies are warranted to investigate the value RRI to guide therapeutic management and impact of such strategies on acute kidney injury incidence and severity.

\section{References}

1. Nash K, Hafeez A, Hou S (2002) Hospital-acquired renal insufficiency. Am J Kidney Dis 39(5): 930-936.

2. Senoo T, Motohiro M, Kamihata H, Yamamoto S, Isono T, et al. (2010) Contrast-induced nephropathy in patients undergoing emergency percutaneous coronary intervention for acute coronary syndrome. Am J Cardiol 105(5): 624-628.

3. McCullough PA, Wolyn R, Rocher LL, Levin RN, O'Neill WW (1997) Acute renal failure after coronary intervention: incidence, risk factors, and relationship to mortality. Am J Med 103(5): 368-375.

4. Lameire N, Hoste E (2004) Reflections on the definition, classification, and diagnostic evaluation of acute renal failure. Cur Opin Crit Care10(6): 468-475.

5. Pflueger A, Larson TS, Nath KA, King BF, Gross JM, et al. (2000) Role of Adenosine in Contrast Media-Induced Acute Renal Failure in Diabetes Mellitus. Mayo Clin Proc 75(12): 1275-1283.

6. Russo D, Minutolo R, Cianciaruso B, Memoli B, Conte G, et al. (1995) Early effects of contrast media on renal hemodynamics and tubular function in chronic renal failure. J Am Soc Nephrol 6(5): 1451-1458.

7. Sinning JM, Adenauer V, Scheer AC, Lema Cachiguango SJ, Ghanem A, et al. (2014) Doppler-based renal resistance index for the detection of acute kidney injury and the non-invasive evaluation of paravalvular aortic regurgitation after transcatheter aortic valve implantation. EuroIntervention 9(11): 1309-1316.)

8. Bossard G, Bourgoin P, Corbeau JJ, Huntzinger J, Beydon L, et al. (2011) Early detection of postoperative acute kidney injury by Doppler renal resistive index in cardiac surgery with cardiopulmonary bypass. Br J Anaesth 107(6): 891-898.'

9. Lerolle N, Guérot E, Faisy C, Bornstain C, Diehl JL, et al. (2006) Renal failure in septic shock: predictive value of Doppler-based renal arterial resistive index. Intensive Care Med 32(10): 1553-1559.

10. Mehran R, Aymong ED, Nikolsky E, Lasic Z, Iakovou I, et al. (2004) A simple risk score for prediction of contrast-induced nephropathy after percutaneous coronary intervention: development and initial validation. J Am Coll Cardiol 44(7): 1393-1399]

11. Cockcroft DW, Gault MH (1976) Prediction of creatinine clearance from serum creatinine. Nephron 16(1): 31-41.

12. Cantley LG, Spokes K, Clark B, McMahon EG, Carter J, et al. (1993) Role of endothelin and prostaglandins in radiocontrast-induced renal artery constriction. Kidney Int 44(6): 1217-1223.

13. Pflueger A, Larson TS, Nath KA, King BF, Gross JM, et al. (2000) Role of Adenosine in Contrast Media-Induced Acute Renal Failure in Diabetes Mellitus. Mayo Clin Proc 75(12): 1275-1283.]

14. Lauschke A, Teichgräber UK, Frei U, Eckardt KU, et al. (2006) 'Lowdose' dopamine worsens renal perfusion in patients with acute renal failure. Kidney Int 69(9): 1669-1674).

15. Darmon M, Schortgen F, Vargas F, Liazydi A, Schlemmer B, et al. (2011) Diagnostic accuracy of Doppler renal resistive index for reversibility of acute kidney injury in critically ill patients. Intensive Care Med 37(1): 68-76.'

16. Schnell D, Deruddre S, Harrois A, Pottecher J, Cosson C, et al. (2012) Renal resistive index better predicts the occurrence of acute kidney injury than cystatin C. Shock 38(6): 592-597. 


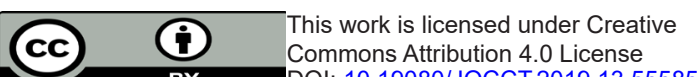

BY DOI: 10.19080/JOCCT.2019.13555854

Your next submission with Juniper Publishers
will reach you the below assets
- Quality Editorial service
- Swift Peer Review
- Reprints availability
- E-prints Service
- Manuscript Podcast for convenient understanding
- Global attainment for your research
- Manuscript accessibility in different formats
( Pdf, E-pub, Full Text, Audio)
- Unceasing customer service
Track the below URL for one-step submission
https://juniperpublishers.com/online-submission.php

